\section{(C) OPEN ACCESS}

\title{
The hypercoagulable profile of patients with stent thrombosis
}

\author{
R Loeffen, ${ }^{1}$ T C Godschalk, ${ }_{1}^{2}$ R van Oerle, ${ }^{1}$ H M H Spronk, ${ }^{1}$ C M Hackeng, ${ }^{3}$ \\ J $\mathrm{M}$ ten Berg, ${ }^{2} \mathrm{H}$ ten Cate $^{1}$
}

'Laboratory for Clinical

Thrombosis and Haemostasis, Departments of Internal

Medicine and Biochemistry, Cardiovascular Research Institute Maastricht, Maastricht University Medical Center, Maastricht, The Netherlands

${ }^{2}$ Department of Cardiology, St. Antonius Center for Platelet Function Research, St. Antonius Hospital, Nieuwegein, The Netherlands ${ }^{3}$ Department of Clinical Chemistry, St. Antonius Center for Platelet Function Research, St. Antonius Hospital, Nieuwegein, The Netherlands

\section{Correspondence to} Rinske Loeffen, Laboratory for Clinical Thrombosis and Haemostasis, Department of Internal Medicine,

Cardiovascular Research Institute Maastricht, Maastricht University Medical Center, P.O. Box 616, Maastricht 6200 MD, The Netherlands; rinske.loeffen@

maastrichtuniversity.nl

RL and TCG contributed equally to this study.

Received 19 August 2014 Revised 22 December 2014 Accepted 5 January 2015 Published Online First 21 May 2015



\section{CrossMark}

\author{
To cite: Loeffen $R$ \\ Godschalk TC, van Oerle $R$ \\ et al. Heart
}

2015;101:1126-1132.

\section{ABSTRACT \\ Objective Coronary stent thrombosis is a devastating} complication after percutaneous coronary intervention $(\mathrm{PCl})$. The mechanisms underlying stent thrombosis are multifactorial. Whether the coagulation system is involved in the pathophysiology of stent thrombosis is unclear. We hypothesised that thrombin generation, reflecting the coagulation potential, is enhanced in patients with stent thrombosis.

Methods A case-control study was performed, including 63 patients with PCl: 23 cases (stent thrombosis) and 40 controls (no stent thrombosis). Thrombin generation was measured using 0, 1 and 5 pM tissue factor (TF) triggers. Active site-inhibited factor VIla (ASIS) and recombinant thrombomodulin were added to study the contact activation system and the protein C pathway, respectively.

Results Thrombin generation was significantly increased for all TF triggers in cases compared with controls. Addition of ASIS to the measurement without exogenous TF revealed significantly enhanced contact activation in cases compared with controls; mean peak height: 241 vs $183 \mathrm{nM}$. Thrombin generation was also significantly increased in cases compared with controls in the presence of exogenous TF; mean peak height: 263 vs $233 \mathrm{nM}(5 \mathrm{pM}$ TF). Addition of thrombomodulin reduced thrombin generation by $23 \%$ in cases and $31 \%$ in controls $(p<0.018)$, suggesting alterations in the protein $C$ pathway in cases.

Conclusions This is the first study that suggests the involvement of the coagulation system in stent thrombosis. Stent thrombosis patients showed a hypercoagulable state, most likely caused by enhanced contact activation and attenuation of anticoagulation by the protein C pathway.

\section{INTRODUCTION}

Coronary stent thrombosis is a rare, but severe, complication after percutaneous coronary intervention (PCI) with stent implantation. This complication manifests itself as myocardial infarction (80\%) and cardiac death (12\%-40\%). Furthermore, stent thrombosis is associated with a high recurrence rate of around $15 \% .^{1-4}$ The incidence of stent thrombosis is approximately $0.5 \%-4 \%$, despite optimal dual antiplatelet therapy with aspirin and an ADP-receptor antagonist. ${ }^{5-7}$ Multiple factors underlie the pathophysiological mechanisms of stent thrombosis. Platelets play a major role in thrombus formation in the coronary stent. This is highlighted by the fact that the most important risk factor is the early discontinuation of clopidogrel. ${ }^{5}$
It is unclear whether the coagulation system, which is closely related to the haemostatic effects of platelets, is also involved in the pathophysiology of stent thrombosis. In the coagulation process, thrombin is the key enzyme, regulating a diversity of procoagulant and anticoagulant responses. Moreover, thrombin is involved in atherosclerosis and atherothrombosis, through the activation of protease-activated receptors (PARs). ${ }^{8} 9$ By activating PAR-1 and PAR-4 on human platelets, thrombin serves as a platelet agonist stimulating platelet secretion and aggregation. ${ }^{10}$ Given the central position of thrombin in haemostasis, useful information about the prothrombotic tendency of a patient can be provided by the potential of the patient's plasma to generate thrombin. ${ }^{11}$ In this study, we hypothesised that plasma thrombin generation is enhanced in patients with a history of stent thrombosis compared with control patients without stent thrombosis.

\section{MATERIAL AND METHODS}

\section{Study design and population}

This was a single-centre case-control study, including consecutive patients who underwent a PCI with stent implantation between August 2007 and March 2011. Selected cases had undergone an index PCI (PCI with initial stent implantation) after which they experienced an angiographically confirmed stent thrombosis during follow-up. ${ }^{12}$ Controls had undergone an index PCI without subsequently suffering from stent thrombosis between the index PCI and blood sampling and did not develop a restenosis in the first 3 months after stenting. Controls were randomly selected from the institution's administrative database. Subjects using oral anticoagulants were excluded. All participants provided written informed consent and the study was conducted according to the principles of the Declaration of Helsinki. The local institutional review board approved the conduct of this study.

\section{Blood collection and preparation}

Blood was collected at the St. Antonius Hospital (Nieuwegein, The Netherlands) between April 2010 and August 2012. A time window of at least 3 months was required between the index PCI (controls) or the PCI for stent thrombosis (cases) and blood sampling. Venous blood was collected from the antecubital vein using 21-gauge needles and $3.2 \%(\mathrm{w} / \mathrm{v})$ sodium citrate Vacuette tubes (Greiner Bio-one, Frickenhausen, Germany). The first $5 \mathrm{~mL}$ of free-flowing blood was discarded to 
avoid haemostatic activation. Platelet-poor plasma (PPP) was obtained by two separate centrifugation steps of $10 \mathrm{~min}$ at $150 \times g$, followed by $10 \mathrm{~min}$ at $16.000 \times \mathrm{g}$. All aliquots were stored at $-80^{\circ} \mathrm{C}$ until analysis.

\section{Thrombin generation}

Thrombin generation in human PPP was measured by means of the calibrated automated thrombogram (CAT) method (Thrombinoscope BV, Maastricht, The Netherlands), exactly according to our previously described standardised protocol. ${ }^{13}$ The CAT method is an in vitro plasma assay that reflects the overall tendency of a plasma sample to clot and provides quantification of the total amount of thrombin formed. Coagulation was activated by the addition of tissue factor (TF), phospholipids (PLs) and calcium chloride. Thrombin activity was monitored via the conversion of a low-affinity fluorogenic substrate for thrombin added to the plasma. Thrombin generation measurements were performed under different experimental conditions to study the specific aspects of the coagulation cascade. Measurements were performed with addition of 0,1 and $5 \mathrm{pM}$ TF together with $4 \mu \mathrm{M}$ PLs (All CAT reagents were obtained from Thrombinoscope BV). By measuring thrombin generation in the absence of TF and presence of the extrinsic pathway inhibitor active side inhibited factor FVIIa (ASIS Novo Nordisk, Bagsvaerd, Denmark; final concentration $30 \mathrm{nM}$ ) the contribution of the intrinsic coagulation pathway was determined. Furthermore, to investigate the function of the protein $\mathrm{C}$ pathway, $0.58 \mathrm{nM}$ recombinant thrombomodulin was added to the $1 \mathrm{pM}$ TF measurements, sufficient to inhibit thrombin generation in platelet-poor normal pooled plasma by $50 \%$. Normal pooled plasma was collected at the Maastricht University Medical Center (Maastricht, The Netherlands) by pooling PPPs from 80 healthy volunteers. Measurements were performed after $10 \mathrm{~min}$ of preheating at $37^{\circ} \mathrm{C}$ in the fluorometer (Fluoroskan, Thermo Labsystems OY, Helsinki, Finland), as described. ${ }^{13}$ Intra-assay and inter-assay CVs for the 1 and $5 \mathrm{pM}$ TF measurements were $10 \%$ and $15 \%$, and $6 \%$ and $10 \%$, respectively. ${ }^{13} \mathrm{~A}$ typical thrombin generation curve and its parameters, obtained after triggering coagulation with TF, are presented in figure 1 .

\section{Thrombin-antithrombin complexes, fibrinogen, D-dimer}

Plasma concentrations of fibrinogen and D-dimer were established using a Sysmex CA-7000 System Automated Coagulation Analyser with reagents obtained from Siemens Healthcare Diagnostics (Marburg, Germany). Fibrinogen was measured according to the Clauss method (intra-assay and inter-assay CVs: $10 \%)^{14}$ and D-dimer levels were determined by the INNOVANCE D-dimer assay (intra-assay and inter-assay CVs: 10\%). Thrombin-antithrombin (TAT) complexes were quantified by a commercially available immunoassay (Enzygnost TAT Micro, Siemens Healthcare Diagnostics, Marburg, Germany) (intra-assay and inter-assay CVs: 6\% and 10\%).

\section{Statistical analysis}

Analyses were performed with PRISM for Mac, V.5.00 (GraphPad Software, San Diego, California, USA), and SPSS V.21.0 (SPSS, Chicago, Illinois, USA). Data are expressed as mean \pm SD or median $\pm \mathrm{IQR}$ (D'Agostino \& Pearson omnibus normality test), and categorical data as frequencies (\%). The time-independent parameters endogenous thrombin potential (ETP) and peak height are expressed as percentage of normal pooled plasma. ${ }^{15}$ Differences between the groups were analysed using a $\chi^{2}$ test, unpaired Student's $t$ test or Mann-Whitney U test as appropriate. Thrombin generation levels were categorised based on the cut-off values of the quartiles in the control group.



Figure 1 Thrombin generation curve and parameters. Example of a thrombin generation curve obtained by means of the calibrated automated thrombogram method in a healthy individual. The main parameters derived from the curve are: (1) the lag time (the time until one-sixth of the peak height is reached), which approximates the clotting time, (2) the peak height or maximum amount of thrombin formed (in $\mathrm{nM}$ thrombin), (3) the endogenous thrombin potential or area under the curve, corresponding to the total amount of thrombin formed (ETP in nM.min), (4) the time until the peak height is reached or time to peak, (5) the velocity index, which reflects the rate of thrombin formation, and (6) the time to tail or the time until the end point of thrombin generation (in $\mathrm{nM} / \mathrm{min}$ ).

The association between thrombin generation and history of stent thrombosis was assessed by logistic regression analysis with either the highest or the lowest quartile as a reference category. Potential confounders (baseline characteristics with a $\mathrm{p}$ value $\leq 0.1$ in $\chi^{2}$ tests) were entered in a multivariate model. ORs are presented with $95 \%$ CIs. A two-tailed probability value $\mathrm{p}<0.05$ was considered statistically significant.

\section{RESULTS}

\section{Patients and blood sampling}

Twenty-three patients with a history of stent thrombosis were included. Seven patients suffered from early stent thrombosis ( $\leq 30$ days post-PCI; two acute $(<24 \mathrm{~h})$, five subacute $(1-$ 30 days)) and 16 from late stent thrombosis ( $>30$ days post-PCI; two late ( $>30$ days), 14 very late (>12 months)). Cases were compared with 40 control patients without a history of stent thrombosis. Baseline characteristics of both groups are summarised in table 1 . More cases than controls were smoking at the time of the index PCI $(p=0.014)$. The mean time interval between stent thrombosis (cases) or index PCI (controls) and blood sampling was 53.9 (36.7-71.2) and 53.2 (29.9-71.9) months, respectively (table 2). At the time of blood collection, more cases $(68.2 \%)$ were on a dual antiplatelet regimen than controls $(25.0 \%)(p=0.001)$, because clopidogrel or prasugrel therapy was continued beyond the standard duration of 1 year for patients who suffered from stent thrombosis.

\section{Coagulation activation}

Plasma concentrations of TAT complexes, fibrinogen and D-dimer were not significantly different between cases and controls (table 2). With the exception of TAT levels in cases, all median plasma levels were within the normal reference ranges. Only in cases median TAT levels were above the reference range of $4.2 \mu \mathrm{g} / \mathrm{L}(6.66(2.56-22.03)$ vs $2.68 \mu \mathrm{g} / \mathrm{L}(1.72-25.67)$, respectively). In $62 \%$ of cases and $39 \%$ of controls, TAT levels 
Table 1 Baseline characteristics of cases and controls at time of index $\mathrm{PCl}$

\begin{tabular}{|c|c|c|c|}
\hline no./total no. (\%) & $\begin{array}{l}\text { Cases }(n=23) \\
\text { no./total no. }(\%)\end{array}$ & Controls $(n=40)$ & p Value \\
\hline \multicolumn{4}{|l|}{ Clinical characteristics } \\
\hline Female & 4/23 (17.4) & $5 / 40(12.5)$ & 0.59 \\
\hline Age (years) & $53.1 \pm 8.6$ & $56.8 \pm 10.1$ & 0.16 \\
\hline Body mass index $\left(\mathrm{kg} / \mathrm{m}^{2}\right)$ & $27.1 \pm 3.7$ & $26.7 \pm 3.4$ & 0.69 \\
\hline Current smoking & $16 / 22(72.7)$ & $16 / 40(40.0)$ & 0.014 \\
\hline Hypertension & $10 / 23(43.5)$ & 9/39 (23.1) & 0.092 \\
\hline Diabetes mellitus & $3 / 23(13.0)$ & $4 / 40(10.0)$ & 0.71 \\
\hline Hypercholesterolaemia & $12 / 23(52.2)$ & $14 / 36(38.9)$ & 0.32 \\
\hline Family history of CAD & $16 / 22(72.7)$ & $23 / 40(57.5)$ & 0.24 \\
\hline \multicolumn{4}{|l|}{ Medical history } \\
\hline Prior MI & $7 / 23(30.4)$ & $9 / 40(22.5)$ & 0.49 \\
\hline Prior $\mathrm{PCl}$ & $5 / 23(21.7)$ & $9 / 40(22.5)$ & 0.94 \\
\hline Prior $C A B G$ & $0 / 23(0.0)$ & $1 / 40(2.5)$ & 0.45 \\
\hline Malignancy & $0 / 23(0.0)$ & $3 / 40(7.5)$ & 0.18 \\
\hline \multicolumn{4}{|l|}{ LVEF } \\
\hline$>45 \%$ & $16 / 18(88.9)$ & 21/27 (77.8) & 0.17 \\
\hline $30 \%-45 \%$ & $1 / 18(5.6)$ & $6 / 27(22.2)$ & \\
\hline$<30 \%$ & $1 / 18(5.6)$ & $0 / 27(0.0)$ & \\
\hline \multicolumn{4}{|l|}{ Indication } \\
\hline Stable angina & $7 / 23(30.4)$ & $16 / 40(40.0)$ & 0.60 \\
\hline UAP/NSTEMI & $7 / 23(30.4)$ & $8 / 40(20.0)$ & \\
\hline STEMI & 9/23 (39.1) & $16 / 40(40.0)$ & \\
\hline \multicolumn{4}{|l|}{ Angiographic data } \\
\hline \multicolumn{4}{|l|}{ Culprit vessel } \\
\hline RCA & $7 / 23(30.4)$ & $15 / 40(37.5)$ & 0.077 \\
\hline LAD & $15 / 23(65.2)$ & $16 / 40(40.0)$ & \\
\hline $\mathrm{RCX}$ & $1 / 23(4.3)$ & $9 / 40(22.5)$ & \\
\hline \multicolumn{4}{|l|}{ Procedural characteristics } \\
\hline BMS & $7 / 23(30.4)$ & $13 / 40(32.5)$ & 0.92 \\
\hline DES-1st generation & $11 / 23(47.8)$ & $17 / 40(42.5)$ & \\
\hline DES-2nd generation & $5 / 23(21.7)$ & $10 / 40(25.0)$ & \\
\hline Total stent length $(\mathrm{mm})$ & $23(18-40)$ & $20(15-27)$ & 0.098 \\
\hline \multicolumn{4}{|l|}{ Antiplatelet therapy } \\
\hline GP IIb/Illa therapy & 4/23 (17.4) & $7 / 40(17.5)$ & 0.99 \\
\hline Aspirin & $20 / 21(95.2)$ & $39 / 40(97.5)$ & 0.64 \\
\hline Clopidogrel & $19 / 21(90.5)$ & $36 / 40(90.0)$ & 0.95 \\
\hline
\end{tabular}

Continuous data are presented as mean $\pm \mathrm{SD}$ or median $\pm \mathrm{IQR}$ and group comparison of continuous data was performed using unpaired Student's t test or Mann-Whitney $\mathrm{U}$ test. Categorical variables are presented as no./total no. (\%), with differences between the groups tested with $\chi^{2}$.

$B M S$, bare metal stents; $C A B G$, coronary artery bypass graft; $C A D$, coronary artery disease; DES, drug eluting stents; GP, glycoprotein; LAD, left anterior descending; $\mathrm{MI}_{\text {, }}$ myocardial infarction; NSTEMI, non-ST-segment elevated myocardial infarction; PCI, percutaneous coronary intervention; RCA, right coronary artery; RCX, ramus circumflexus; STEMI, ST-segment elevated myocardial infarction; UAP, unstable angina pectoris.

were $>4.2 \mu \mathrm{g} / \mathrm{L}$, indicating that active coagulation was ongoing or had recently occurred in a substantial subgroup of patients.

\section{Coagulation potential}

Contact activation pathway

The results of the $0 \mathrm{pM}$ TF measurements in the absence of ASIS showed an enhanced thrombin generation in cases compared with controls (data not shown). For measurements in the presence of ASIS the difference in thrombin generation between cases and controls was even more pronounced (figure 2). Cases demonstrated a shortening in lag time, time to peak and time to tail (median 9.2 (8.1-10.6) vs $12.7 \mathrm{~min}(11.5-16.7), \mathrm{p}<0.0001 ; 11.7$ (10.5-13.5) vs $16.1 \mathrm{~min}(14.3-20.5), \mathrm{p}<0.0001$; mean $24.4 \pm 2.9$ vs 31.7 $\pm 4.5 \mathrm{~min}, \mathrm{p}<0.0001$; respectively). Furthermore, cases showed an increased peak height and velocity index compared with controls (mean $241 \pm 54$ vs $183 \pm 60 \mathrm{nM}, \mathrm{p}=0.0005$; $98 \pm 35$ vs 63 $\pm 28 \mathrm{nM} / \mathrm{min}, \mathrm{p}=0.0002$; respectively). Although the ETP was higher in cases, no significant difference was found compared with controls (mean $1131 \pm 156$ vs $1026 \pm 228 \mathrm{nM} / \mathrm{min}, \mathrm{p}=0.069$ ). Overall, the results of the $0 \mathrm{pM}$ TF measurements with addition of ASIS demonstrated a significantly enhanced contact activation in cases compared with controls. These results were confirmed by the data from the $1 \mathrm{pM}$ TF trigger (data not shown).

\section{Protein C pathway}

The inhibition of thrombin generation by addition of thrombomodulin resulted only in a moderate ETP reduction $(<50 \%)$ in both cases and controls (figure 3). However, compared with controls, cases showed a lower ETP reduction upon thrombomodulin addition (mean $31 \pm 12 \%$ vs $23 \pm 13 \%, \mathrm{p}=0.018$, respectively), suggesting alterations in the protein $\mathrm{C}$ pathway for patients with stent thrombosis. Similar to the $0 \mathrm{pM}$ TF \pm ASIS and $1 \mathrm{pM}$ TF trigger, thrombin generation measurements in the presence of thrombomodulin demonstrated accelerated and increased thrombin generation in cases compared with controls. This was shown by a shortened lag time, time to peak and time to tail (mean $5.3 \pm 1.2$ vs $6.0 \pm 1.2 \mathrm{~min}$, $\mathrm{p}=0.025 ; 8.2 \pm 1.3$ vs $9.1 \pm 1.1 \mathrm{~min}, \mathrm{p}=0.007$; median 20.5 (19.0 21.0) vs $21.0 \mathrm{~min}$ (20.1-22.0), $\mathrm{p}=0.034$; respectively), and an increased ETP, peak height and velocity index (mean $196 \pm 59$ vs 159 $\pm 56 \mathrm{nM}, \mathrm{p}=0.015 ; 929 \pm 243$ vs $779 \pm 239, \mathrm{p}=0.002$; median 64 $(47-84)$ vs $54 \mathrm{nM} / \mathrm{min}$ (32-66), $\mathrm{p}=0.04$; respectively).

\section{Extrinsic pathway}

Even when analyses were performed at the higher TF concentration of $5 \mathrm{pM}$, cases demonstrated a significantly enhanced thrombin generation compared with controls (figure 4). Overall, in the $5 \mathrm{pM}$ TF assay the time-dependent variables, lag time (not significant), time to peak and time to tail were shortened in cases compared with controls (mean $2.8 \pm 0.5$ vs $3.0 \pm 0.6 \mathrm{~min}, \mathrm{p}=0.114 ; 5.5 \pm 0.8$ vs $6.1 \pm 0.8 \mathrm{~min}, \mathrm{p}=0.013$; $19.1 \pm 2.1$ vs $20.6 \pm 1.8 \mathrm{~min}, \mathrm{p}=0.007$; respectively). Moreover, an increased normalised peak height and velocity index was demonstrated in cases compared with controls (mean 220 $\pm 33 \%$ vs $192 \pm 31 \%, \mathrm{p}=0.002 ; 101 \pm 30$ vs $80 \pm 25 \mathrm{nM} / \mathrm{min}$, $\mathrm{p}=0.004$; respectively). In contrast, the small difference in normalised ETP between cases and controls was not significant (mean $138 \pm 17 \%$ vs $136 \pm 19 \%, p=0.76$ ). We observed no significant difference in thrombin generating potential (all triggers) between early $(n=7)$ and late $(n=16)$ stent thrombosis (data not shown).

\section{Thrombin generation and the risk of stent thrombosis}

Overall, in patients who underwent a PCI, an enhanced and accelerated thrombin generation was independently associated with a history of stent thrombosis (table 3). However, ORs were not significant for all thrombin generation parameters and associations varied across the different TF triggers. Both the peak height and time to tail were the parameters with significant associations for all three TF triggers. Adjustment for the potential confounders hypertension, stent length, culprit vessel and smoking (baseline characteristics with a $\mathrm{p}$ value $\leq 0.1$ in $\chi^{2}$ tests) resulted in an improvement of the model fit (likelihood ratio) and for most thrombin generation parameters in an enhancement of the ORs (table 3). Most of the enhancement was explained by the confounder hypertension, whereas the effects of the stent length, culprit vessel and smoking were small (separate models not shown). 
Table 2 Characteristics at the time of blood sampling for cases and controls

\begin{tabular}{|c|c|c|c|}
\hline no./total no. (\%) & $\begin{array}{l}\text { Cases }(n=23) \\
\text { no./total no. }(\%)\end{array}$ & Controls $(n=40)$ & p Value \\
\hline Time between index $\mathrm{PCl}$ and blood sampling (months) & $53.9(36.7-71.2)$ & $53.2(29.9-71.9)$ & 0.81 \\
\hline \multicolumn{4}{|l|}{ Medication } \\
\hline DAPT & $16 / 23(69.6)$ & $9 / 40(22.5)$ & $<0.001$ \\
\hline Aspirin & $23 / 23(100.0)$ & $38 / 40(95.0)$ & 0.28 \\
\hline Clopidogrel & $13 / 23(56.5)$ & $8 / 40(20.0)$ & 0.003 \\
\hline Prasugrel & $3 / 23(13.0)$ & $1 / 40(2.5)$ & 0.10 \\
\hline Statins & $22 / 22(100.0)$ & $35 / 39(89.7)$ & 0.12 \\
\hline ACE inhibitors & $15 / 22(68.2)$ & $19 / 39(48.7)$ & 0.15 \\
\hline \multicolumn{4}{|l|}{ Laboratory measurements } \\
\hline Platelet count $\left(\times 10^{9} / \mathrm{L}\right)$ & $204 \pm 48$ & $215 \pm 53$ & 0.42 \\
\hline Creatinine ( $\mu \mathrm{mol} / \mathrm{L})$ & $80(66-91)$ & $79(73-84)$ & 0.64 \\
\hline \multicolumn{4}{|l|}{ Coagulation measurements } \\
\hline TAT $(\mu g / L)$ & $6.7(2.6-22.0)$ & $2.7(1.7-25.7)$ & 0.12 \\
\hline D-dimer (mg/L) & $0.41(0.27-0.55)$ & $0.38(0.25-0.59)$ & 0.99 \\
\hline Fibrinogen (g/L) & $3.53 \pm 0.70$ & $3.48 \pm 0.74$ & 0.80 \\
\hline
\end{tabular}

\section{DISCUSSION}

The main finding of the present case-control study is a significantly faster and higher thrombin generation in plasma from patients with a history of stent thrombosis compared with control patients. In patients with a history of stent thrombosis, a shift towards a hypercoagulable state is seen, which was found for all thrombin generation measurements $(0,1$ and $5 \mathrm{pM} \mathrm{TF})$. As demonstrated by the addition of ASIS, the prothrombotic profile in cases is partly due to significantly enhanced intrinsic contact activation. In addition, cases demonstrated a reduced anticoagulant function of the protein $\mathrm{C}$ pathway, as shown by the significantly lower ETP reduction upon thrombomodulin addition.
Furthermore, logistic regression analysis revealed that in patients who underwent a PCI, increased and accelerated thrombin generation levels are associated with a history of stent thrombosis.

Although patients with a history of stent thrombosis demonstrated a significantly enhanced thrombin potential, which is considered as hypercoagulability, we found no elevation in fibrinogen and the thrombin activation markers TAT and D-dimer. This might be explained by the relatively long time interval between stent thrombosis and blood collection (mean time interval 56.7 months). Plasma thrombin generation analyses assess the prothrombotic tendency of a patient, which is not primarily linked to the extent of thrombin formation in the body. Therefore, the
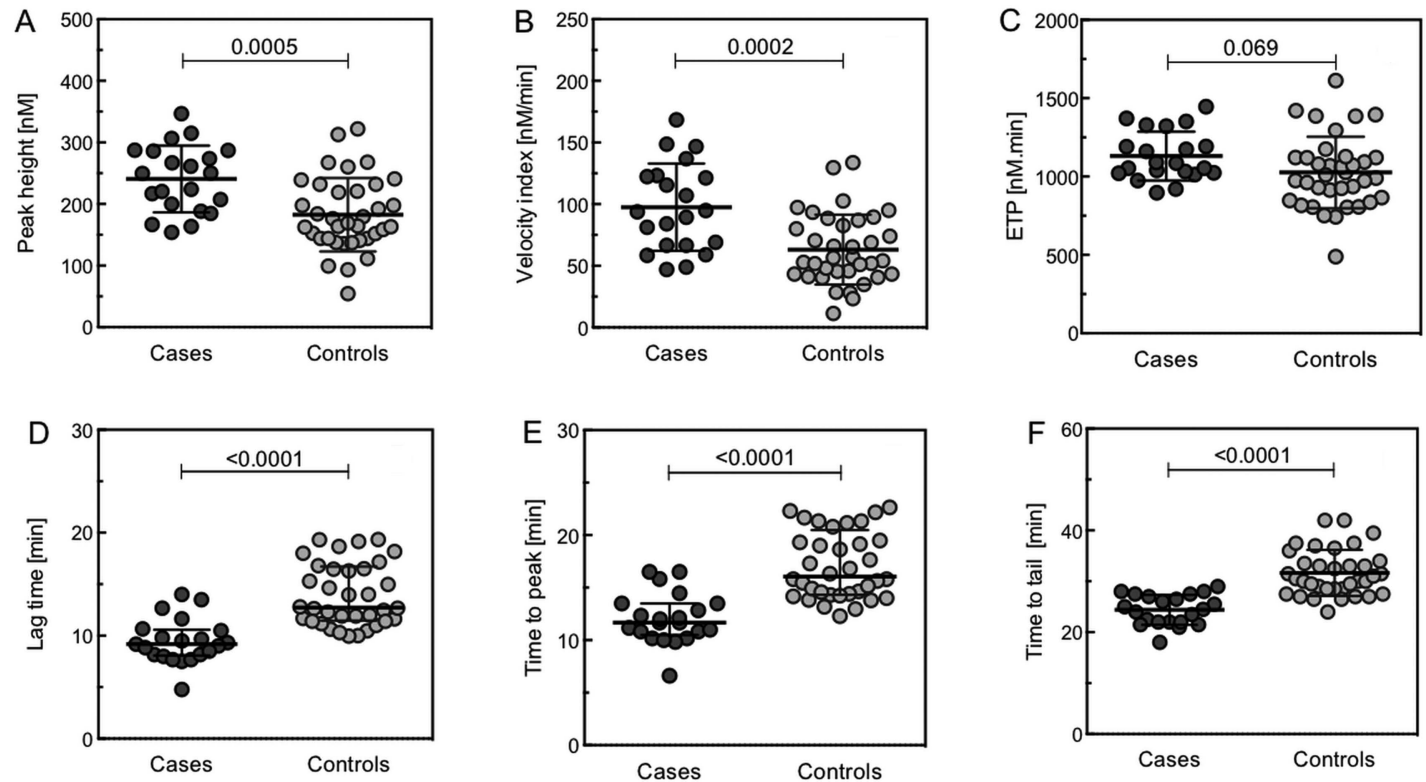

Figure 2 The influence of ASIS on thrombin generation in cases versus controls. Thrombin generation analysis (0 pM TF) of PPP collected from 23 cases and 40 controls upon addition of ASIS. Upper panel: peak height in nM thrombin (A), velocity index in $\mathrm{nM} / \mathrm{min}$ (B) and ETP in nM.min (C). Lower panel: lag time in min (D), time to peak in min (E), and time to tail in min (F). Horizontal lines indicate means $\pm S D(A-C$ and $E)$, or medians \pm IQR (D and F). ASIS, active site-inhibited factor VIla; PPP, platelet poor plasma; ETP, endogenous thrombin potential; TF, tissue factor. 


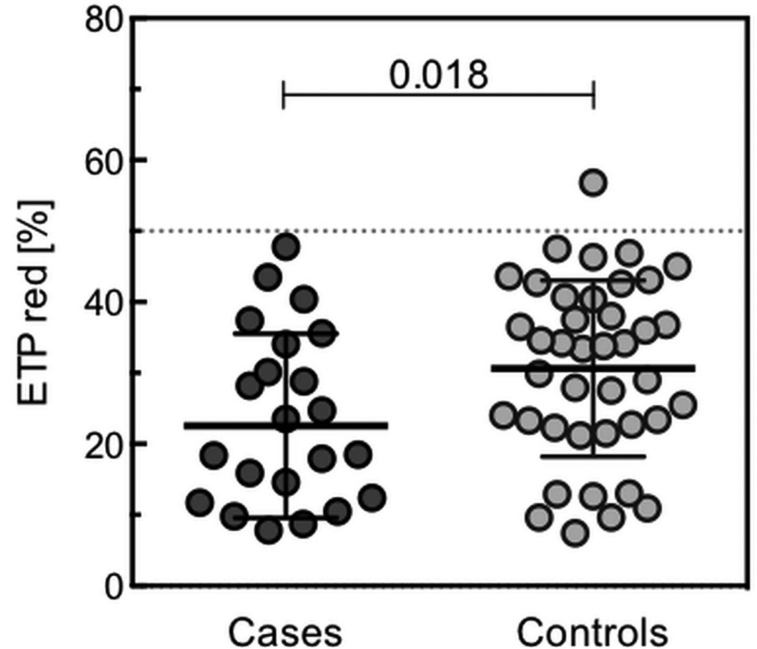

Figure 3 The effect of thrombomodulin on thrombin generation in cases and controls. Thrombin generation analysis (1 pM TF) of PPP collected from 23 cases and 40 controls upon addition of thrombomodulin titrated at an ETP reduction of $50 \%$ in normal pooled plasma (horizontal dotted line). Depicted are the percentage reductions in ETP calculated for cases and controls. PPP, platelet poor plasma; ETP, endogenous thrombin potential; TF, tissue factor.

thrombin generation potential may be persistently elevated in patients after stent thrombosis, while the levels of thrombin activation markers and fibrinogen are normal.

An important finding in our study was the enhanced thrombin generation in the presence of an inhibitor of the extrinsic pathway, suggesting the presence of contact activation in patients with a history of stent thrombosis. Activation of factor XII may be an important determinant of arterial thrombosis, where platelet activation and the presence of specific agonists of contact activation including polyphosphates may be locally active in strengthening clot structure. ${ }^{16-18}$ Another new finding in our study was the impaired downregulation of thrombin formation via the protein $\mathrm{C}$ pathway for both cases and controls, which was more pronounced in cases. The mechanisms underlying this apparent resistance against activated protein $\mathrm{C}$ are unclear, but could be very relevant. Activated protein $\mathrm{C}$ is thought to play a protective role against arterial thrombosis through its anti-inflammatory and antiapoptotic properties. ${ }^{19}$ Previous studies have shown that low activated protein $\mathrm{C}$ levels are associated with early myocardial infarction and with the extent and severity of atherosclerosis. ${ }^{20} 21$

At the time of the index PCI (no data available on smoking rate at the time of blood sampling) there was a higher rate of smoking in cases versus controls. However, the difference in ETP between smokers and non-smokers was only minimal and could be explained by the intra-assay variation of the CAT assay. Literature does not show any unequivocal effects of smoking on plasma thrombin generation. ${ }^{22}{ }^{23}$ Furthermore, in the present study, we demonstrated by multivariate logistic regression analysis that smoking had no clear effect on thrombin generation. At the time of blood collection, more cases than controls were on dual antiplatelet therapy, because, for patients who suffered from stent thrombosis, clopidogrel or prasugrel therapy was continued beyond the standard duration of 1 year after PCI. However, an effect of platelets function inhibitors on thrombin generation is not to be expected, considering all measurements were performed in PPP. Also, in a previous study, it was observed that aspirin did not affect any of the thrombin generation variables. ${ }^{24}$ Although there might be differences in the pathogenesis of early and late stent thrombosis, we found no difference in thrombin generation potential between the different types of stent thrombosis. However, for performing subgroup analysis the groups were rather small.

The recurrence rate of stent thrombosis in this cohort was $13 \%$, which is comparable to the literature. ${ }^{4}$ Obviously, inadequate P2Y12 inhibition with the use of clopidogrel may still have been a major factor in the occurrence of stent thrombosis.
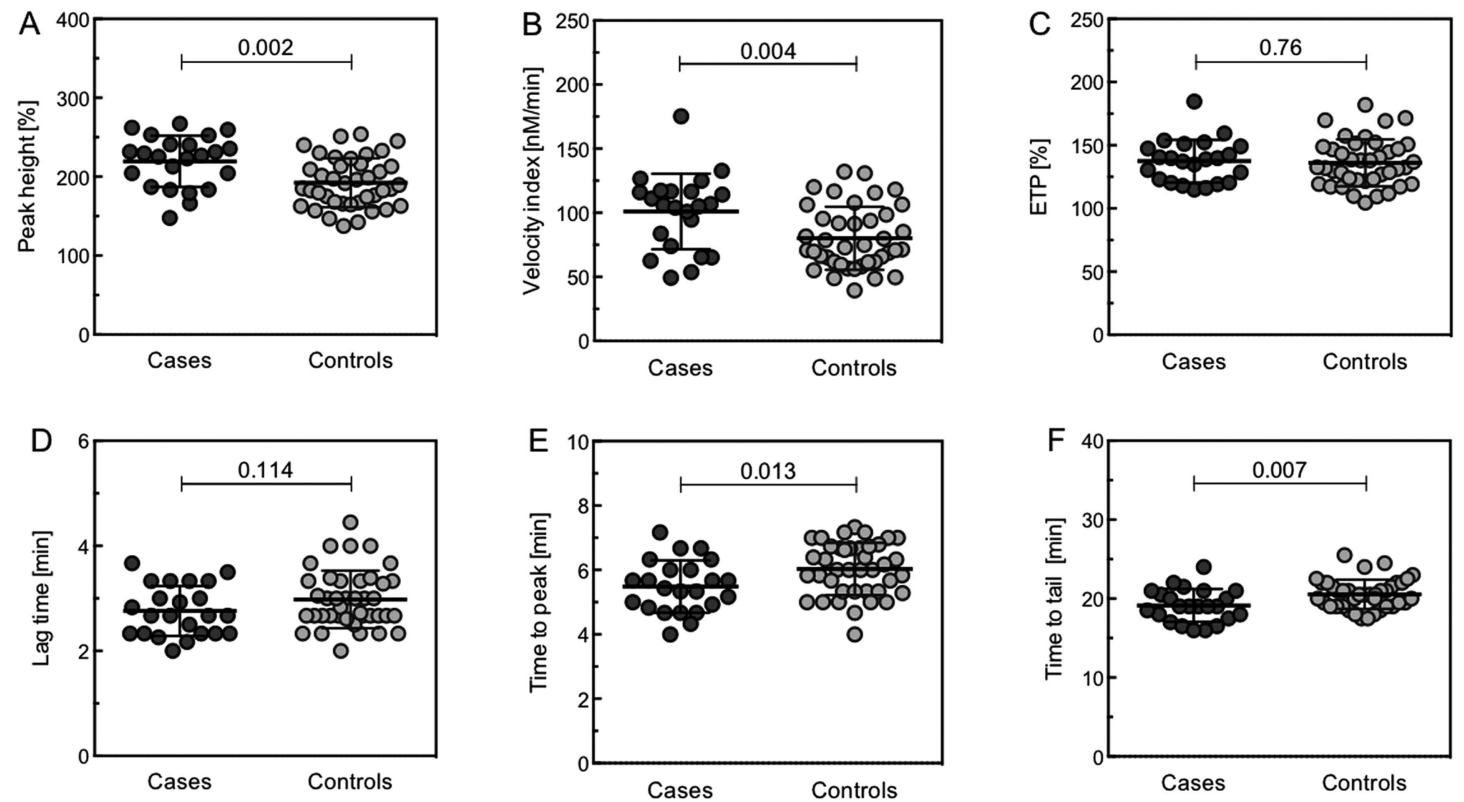

Figure 4 Thrombin generation measurements at $5 \mathrm{pM}$ TF in cases versus controls. Thrombin generation analysis (5 pM TF) of PPP collected from 23 cases and 40 controls. Upper panel: peak height in $\mathrm{nM}$ thrombin (A), velocity index in $\mathrm{nM} / \mathrm{min}$ (B) and ETP in $\mathrm{nM}$.min (C). Lower panel: lag time in $\min (D)$, time to peak in $\min (E)$ and time to tail in $\min (F)$. Horizontal lines indicate means \pm SD. PPP, platelet poor plasma; ETP, endogenous thrombin potential; TF, tissue factor. 


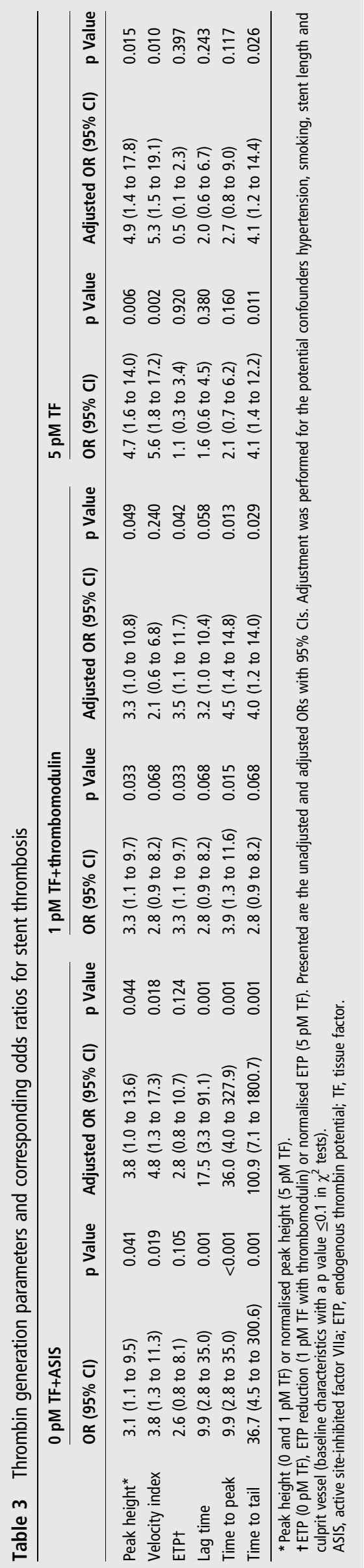

However, the observed hypercoagulable state (in PPP) of patients with a history of stent thrombosis in this study suggests that the coagulation system might be an additional target for reducing the high recurrence rate of stent thrombosis. Thrombin has a central role in the coagulation system and is also a potent stimulant of platelet aggregation. Inhibition of thrombin, for example, by a combination of a low dose of a non-vitamin $\mathrm{K}$ oral anticoagulant and one ADP-receptor antagonist, might theoretically be able to reduce the recurrence rate of stent thrombosis. ${ }^{25}$ The efficacy and certainly also the bleeding risks associated with such combined antithrombotic therapy need to be demonstrated in further clinical study. Another potentially attractive therapeutic target might be the contact activation system, in particular factor XIIa. Factor XII-deficient animals are protected from arterial thrombosis and, like factor XII-deficient humans, do not display an increased bleeding tendency. ${ }^{26}{ }^{27}$ Specific factor XIIa inhibitors are promising agents to block thrombosis without apparent effect on bleeding in different recent experimental studies. ${ }^{28}{ }^{29}$ In the hope of reducing the recurrence rate of stent thrombosis without increasing the risk of bleeding, factor XIIa inhibitors might be promising therapeutic agents alongside antiplatelet therapy in patients with a history of stent thrombosis.

The present study has certain limitations. First, the number of patients included was small, which makes extrapolation to the total population of patients with PCI difficult. However, given the incidence of stent thrombosis of $0.5 \%-4 \%$, the sample size can be considered representative for a large-sized Dutch hospital. Second, stent thrombosis occurred several years prior to blood collection, which makes it unclear whether the hypercoagulable state was also present at the time of stent thrombosis. Third, data were missing on smoking status at the time of blood sampling. However, based on literature and as demonstrated in the present study by multivariate logistic regression analyses, we do not expect a clear effect of current smoking status on thrombin generation. Fourth, blood was sampled into citrate blood collection tubes without corn trypsin inhibitor (CTI). CTI inhibits activated factor XII and can be used to inhibit preanalytical contact activation in plasma. However, addition of CTI to the blood collection tubes can also be considered a drawback, since it will also inhibit any activated factor XII that was formed in vivo, which makes it difficult to investigate the contribution of in vivo contact activation on thrombin generation. Finally, the development of whole blood assays may help to improve the application of thrombin generation analysis in patients with arterial disease in the future, because the presence of platelets and other cells may better reflect the conditions that predispose to arterial thrombosis. ${ }^{30}$

\section{CONCLUSION}

Coronary stent thrombosis has a multifactorial origin and, in contrast to the known involvement of platelets, the potential role of the coagulation system is largely unknown. Our study is the first to demonstrate an increased thrombin generation potential, as well as a reduced capacity to activate protein $\mathrm{C}$ in patients with a history of stent thrombosis. This shift towards a hypercoagulable state, which is most likely caused by an enhanced contact activation and attenuation of anticoagulation by the protein $\mathrm{C}$ pathway, might contribute to the pathophysiology of stent thrombosis. The development of novel specific anticoagulants, including against factor XIIa, will potentially enable additional antithrombotic therapy beyond platelet inhibitors. 


\section{Key messages}

What is already known on this subject?

- Platelets play an important role in the pathophysiology of stent thrombosis.

- Despite current dual antiplatelet therapy, stent thrombosis is associated with a high recurrence rate.

- The potential role of the coagulation system in the pathophysiology of stent thrombosis is largely unknown.

\section{What might this study add?}

- Patients with a history of stent thrombosis have an increased thrombin generating potential.

- The hypercoagulable state is due to enhanced intrinsic contact activation and reduced capacity to activate protein C.

\section{How might this impact on clinical practice?}

- The coagulation system might be a useful additional therapeutic target to reduce the high recurrence rate of stent thrombosis.

Funding This research was performed within the framework of CTMM, the Center for Translational Molecular Medicine (http://www.ctmm.nl), project INCOAG (grant 01(-201), and supported by the Dutch Heart Foundation.

Competing interests None.

Patient consent Obtained.

Ethics approval The local institutional review board of the St. Anthonius Hospital Nieuwegein approved the conduct of this study.

Provenance and peer review Not commissioned; externally peer reviewed.

Open Access This is an Open Access article distributed in accordance with the Creative Commons Attribution Non Commercial (CC BY-NC 4.0) license, which permits others to distribute, remix, adapt, build upon this work non-commercially, and license their derivative works on different terms, provided the original work is properly cited and the use is non-commercial. See: http://creativecommons.org/ licenses/by-nc/4.0/

\section{REFERENCES}

1 Dangas GD, Caixeta A, Mehran R, et al. Frequency and predictors of stent thrombosis after percutaneous coronary intervention in acute myocardial infarction. Circulation 2011;123:1745-56.

2 de la Torre-Hernandez JM, Alfonso F, Hernandez F, et al. Drug-eluting stent thrombosis: results from the multicenter Spanish registry ESTROFA (Estudio ESpanol sobre TROmbosis de stents FArmacoactivos). J Am Coll Cardiol 2008;51:986-90.

3 lakovou I, Schmidt T, Bonizzoni E, et al. Incidence, predictors, and outcome of thrombosis after successful implantation of drug-eluting stents. JAMA 2005;293:2126-30.

4 van Werkum JW, Heestermans AA, de Korte FI, et al. Long-term clinical outcome after a first angiographically confirmed coronary stent thrombosis: an analysis of 431 cases. Circulation 2009;119:828-34.

5 van Werkum JW, Heestermans AA, Zomer AC, et al. Predictors of coronary stent thrombosis: the Dutch Stent Thrombosis Registry. J Am Coll Cardiol 2009:53:1399-409.

6 Wallentin L, Becker RC, Budaj A, et al. Ticagrelor versus clopidogrel in patients with acute coronary syndromes. N Engl J Med 2009;361:1045-57.
7 Wiviott SD, Braunwald E, McCabe $\mathrm{CH}$, et al. Prasugrel versus clopidogrel in patients with acute coronary syndromes. N Engl J Med 2007;357:2001-15.

8 Borissoff Jl, Spronk HM, ten Cate H. The hemostatic system as a modulator of atherosclerosis. N Engl J Med 2011;364:1746-60.

9 Loeffen R, Spronk HM, ten Cate H. The impact of blood coagulability on atherosclerosis and cardiovascular disease. J Thromb Haemost 2012;10:1207-16.

10 Coughlin SR. Thrombin signalling and protease-activated receptors. Nature 2000:407:258-64.

11 Hemker HC, Giesen P, AlDieri R, et al. The calibrated automated thrombogram (CAT): a universal routine test for hyper- and hypocoagulability. Pathophysiol Haemost Thromb 2002;32:249-53.

12 Cutlip DE, Windecker $S$, Mehran $R$, et al. Clinical end points in coronary stent trials: a case for standardized definitions. Circulation 2007:115:2344-51.

13 Loeffen R, Kleinegris MC, Loubele ST, et al. Preanalytic variables of thrombin generation: towards a standard procedure and validation of the method. J Thromb Haemost 2012;10:2544-54.

14 Claus A. Rapid physiological coagulation method in determination of fibrinogen. Acta Haematologica 1957; 17:237-46.

15 Spronk HM, Dielis AW, De Smedt E, et al. Assessment of thrombin generation II: validation of the calibrated automated thrombogram in platelet-poor plasma in a clinical laboratory. Thromb Haemost 2008;100:362-4

16 Konings J, Govers-Riemslag JW, Philippou H, et al. Factor XIla regulates the structure of the fibrin clot independently of thrombin generation through direct interaction with fibrin. Blood 2011;118:3942-51.

17 Kuijpers MJ, van der Meijden PE, Feijge MA, et al. Factor XII regulates the pathological process of thrombus formation on ruptured plaques. Arterioscler Thromb Vasc Biol 2014;34:1674-80.

18 Morrissey JH, Choi SH, Smith SA. Polyphosphate: an ancient molecule that links platelets, coagulation, and inflammation. Blood 2012;119:5972-9.

19 Esmon CT. The anticoagulant and anti-inflammatory roles of the protein C anticoagulant pathway. J Autoimmun 2000;15:113-16.

20 Kiechl S, Muigg A, Santer $P$, et al. Poor response to activated protein $C$ as a prominent risk predictor of advanced atherosclerosis and arterial disease. Circulation 1999;99:614-19.

21 Zorio $E$, Navarro $S$, Medina $P$, et al. Circulating activated protein $C$ is reduced in young survivors of myocardial infarction and inversely correlates with the severity of coronary lesions. J Thromb Haemost 2006:4:1530-6.

22 Bratseth V, Pettersen AA, Opstad TB, et al. Markers of hypercoagulability in CAD patients. Effects of single aspirin and clopidogrel treatment. Thromb J 2012;10:12.

23 Haidl H, Schlagenhauf A, Cimenti C, et al. Regular smoking is not associated with increased thrombin generation in young adults. J Thromb Haemost 2013;11:1433-5.

24 Smid M, Dielis AW, Spronk HM, et al. Thrombin generation in the Glasgow Myocardial Infarction Study. PloS ONE 2013;8:e66977.

25 Gibson CM, Chakrabarti AK, Mega J, et al. Reduction of stent thrombosis in patients with acute coronary syndromes treated with rivaroxaban in ATLAS-ACS 2 TIMI 51. J Am Coll Cardiol 2013:62:286-90.

26 Kleinschnitz C, Stoll G, Bendszus M, et al. Targeting coagulation factor XII provides protection from pathological thrombosis in cerebral ischemia without interfering with hemostasis. J Exp Med 2006;203:513-8.

27 Renne T, Pozgajova M, Gruner $S$, et al. Defective thrombus formation in mice lacking coagulation factor XII. J Exp Med 2005;202:271-81.

28 Hagedorn I, Schmidbauer S, Pleines I, et al. Factor XIla inhibitor recombinant human albumin Infestin-4 abolishes occlusive arterial thrombus formation without affecting bleeding. Circulation 2010;121:1510-17.

29 Larsson M, Rayzman V, Nolte MW, et al. A factor Xlla inhibitory antibody provides thromboprotection in extracorporeal circulation without increasing bleeding risk. Sci Trans/ Med 2014:6:222ra17.

30 Ninivaggi $M$, Apitz-Castro R, Dargaud $Y$, et al. Whole-blood thrombin generation monitored with a calibrated automated thrombogram-based assay. Clin Chem 2012;58:1252-9. 